\title{
Inde, pays protéiforme: là où tout a commencé
}

\section{Nicola Pozza}

\section{OpenEdition}

Journals

Édition électronique

URL : http://journals.openedition.org/edl/2327

DOI : $10.4000 /$ edl.2327

ISSN : 2296-5084

\section{Éditeur}

Université de Lausanne

\section{Édition imprimée}

Date de publication : 15 mars 2020

Pagination : 33-38

ISBN : 978-2-940331-73-4

ISSN : 0014-2026

\section{Référence électronique}

Nicola Pozza, «Inde, pays protéiforme: là où tout a commencé », Études de lettres [En ligne], 312 | 2020, mis en ligne le 24 mars 2020, consulté le 17 septembre 2020. URL : http:// journals.openedition.org/edl/2327 ; DOI : https://doi.org/10.4000/edl.2327 
INDE, PAYS PROTÉIFORME: LÀ OÜ TOUT A COMMENCÉ

Hasards du calendrier ou illustration parlante de l'air du temps, la période consacrée à rédiger ces lignes, mai 2019, est marquée par le triomphe total et sans précédent d'un parti politique indien né en 1980 : le Bharatiya Janata Party (BJP) ou «Parti du peuple indien». En effet, pour la première fois depuis 1984, 2019 voit le parti majoritaire au pouvoir réélu à la majorité absolue - en l'occurrence 303 sièges sur les 542 que compte la Lok Sabha, la chambre basse du Parlement, soit $55,9 \%$ des voix. Avec un taux de participation à faire pâlir d'envie les records suisses: $67,1 \%$, soit 600 millions d'électeurs et électrices tout de même! Un résultat qui conforte encore la mainmise du premier ministre Narendra Modi sur l'agenda politique (libéral et conservateur) et culturel (nationalisme hindou) d'un pays en passe de devenir le plus peuplé au monde.

Loin des projecteurs braqués sur le décès de Roland Barthes, ou sur les derniers jours d'Alfred Hitchcock et de Joe Dassin, le BJP voit donc le jour le 5 avril 1980. Le parti est créé par des politiciens issus des rangs de l'ex-Jana Sangh, "L'Association du peuple indien», représentant la droite hindoue. Il constituait un des groupes formant la coalition hétéroclite du Janata Party, fondée dans le seul but de contrecarrer la politique autocratique d'Indira Gandhi et de ses fidèles partisans au sein du Congrès. Le Janata Party, regroupant le Jana Sangh, le BLD (Bharatiya Lok Dal), le Congrès $(\mathrm{O})$ (formé d'opposants à Indira Gandhi) et le Parti socialiste, était sorti largement vainqueur des urnes en mars 1977, à l'issue d'un des chapitres les plus sombres - et les moins analysés de l'histoire de l'Inde moderne, à savoir l'état d'urgence. Celui-ci fut 
ordonné par Indira Gandhi le 26 juin 1975 en réponse à l'agitation de l'opposition qui réclamait sa démission suite au jugement d'invalidation, par la Haute Cour d'Allahabad, de son élection à la Lok Sabha en 1971 pour "pratiques électorales frauduleuses». L'état d'urgence durera plus d'un an et demi, jusqu'au 18 janvier 1977, date à laquelle la première ministre annonce à la surprise générale des élections anticipées pour mars. Élections que remporta le Janata Party.

Mais deux ans plus tard, suite aux dissensions intestines croissantes de ce "parti» éclectique, nourries des luttes de pouvoir interpersonnelles et de l'absence d'une vision politique et sociale commune, des élections de mi-mandat devinrent inévitables. Le scrutin qui s'ensuivit, en janvier 1980, entraîna la lourde défaite du Janata Party face à l'ennemi commun: le Congrès et sa figure de proue Indira Gandhi. Les membres du Jana Sangh profitèrent de cette défaite électorale pour retrouver une indépendance politique en fondant le BJP, qui se voulait, à ce moment-là de l'Histoire, séculariste et indépendant.

1980 marque donc la naissance d'un parti qui allait dicter la politique indienne pour les décennies à venir et anticiper la montée en puissance des nationalismes identitaires du XXI ${ }^{\mathrm{e}}$ siècle. Mais 1980 signe aussi la renaissance de celle que l'on qualifia de "Dame de fer asiatique» - son alter ego britannique ne faisait alors que ses premiers pas comme première ministre (fig. 1). Indira Gandhi allait en effet diriger le pays de toute son autorité - nourrie d'une paranoïa grandissante à l'égard de tout pouvoir externe à son clan familial - jusqu'à son assassinat le 31 octobre 1984 par ses gardes du corps sikhs. Fille du premier premier ministre de l'Inde indépendante, le très charismatique Jawaharlal Nehru, et maillon fort de la dynastie Nehru-Gandhi - une dynastie sans origine commune avec M. K. Gandhi -, Indira Gandhi était à ce point convaincue de son statut unique qu'elle n'eut de cesse de modeler le parti et le pouvoir à sa mesure.

C'est ainsi qu'après avoir été expulsée de l'omnipotent Congrès "pour indiscipline" par les vétérans du parti le 12 novembre 1969, elle réagit immédiatement en créant, avec l'appui de députés qui lui étaient restés fidèles, une nouvelle faction, le Congrès $(\mathrm{R})-\mathrm{R}$ pour Requisitionists à la base, mais largement considéré comme équivalent à Ruling par la suite. Son parti remporta très largement les élections générales de mars 1971, puis celles de janvier 1980 sous la nouvelle étiquette du Congrès (I) - I pour «Indira». Des victoires dues notamment à l'impact de son 


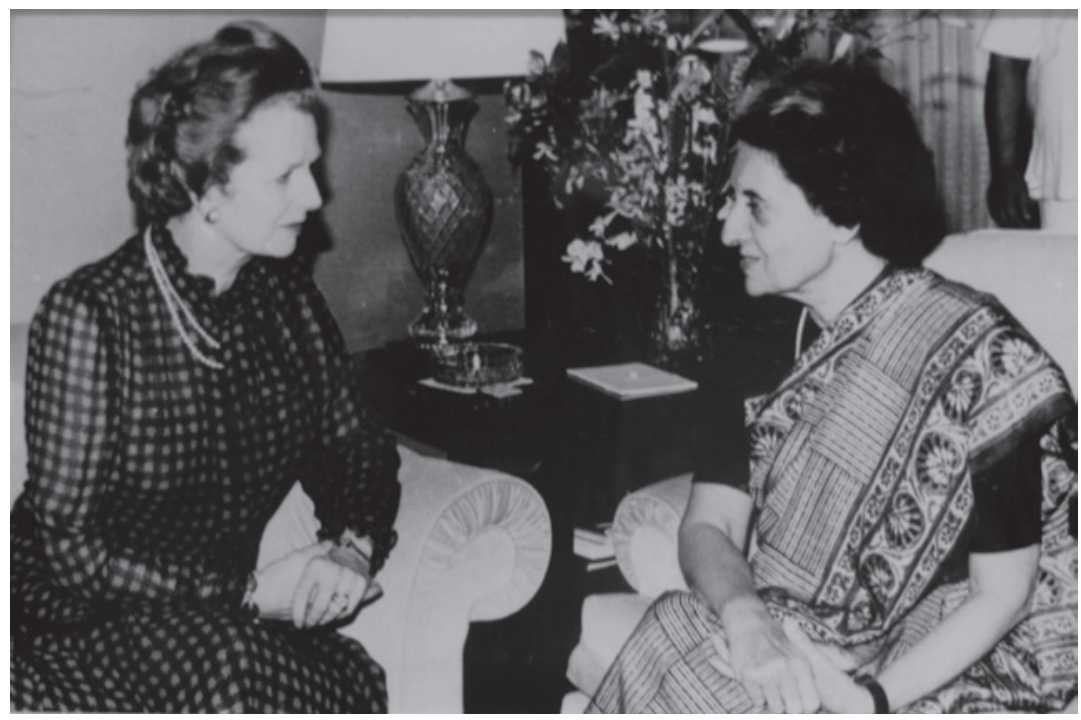

Fig. 1 - La première ministre indienne Indira Gandhi avec la première ministre britannique Margaret Thatcher à Cancun, octobre 1981, FotoFlirt/Alamy Stock Foto, DA19F1.

slogan Garibi Hatao ("supprimez la pauvreté»), qui s'attira dans un premier temps la faveur des classes populaires et défavorisées. Ce slogan, ambitieux mais trompeur, fut ensuite appliqué avec zèle, et à la lettre, durant l'état d'urgence par Sanjay Gandhi, son tristement célèbre fils cadet, censé lui succéder, n'eût été l'accident d'avion qui lui coûta la vie en juin de la même année. Ce slogan continuera de marquer les campagnes politiques ultérieures et demeure plus que jamais d'actualité au $\mathrm{XXI}^{\mathrm{e}}$ siècle dans une Inde qui cherche à briller de mille feux aux yeux du monde (selon la formule India Shining, développée en 2004 par le BJP lui-même). Dans les faits, il s'avère que sa mise en œuvre résulta plus souvent qu'à son tour en l'élimination pure et simple des slums (bidonvilles), et l'expulsion manu militari de leurs résidents, pour bâtir des infrastructures étincelantes correspondant aux standards des World-class cities.

Bien loin des lumières de ces villes du futur, un autre scandale, plus localisé mais non moins dramatique, marqua aussi les esprits de l'Inde de 1980: celui des Bhagalpur blindings («les aveuglements de Bhagalpur»), du nom d'une ville du Bihar où trente-trois hommes en 
détention préventive eurent les yeux brûlés vifs à l'acide par un groupe de policiers pour avoir osé défier le pouvoir en place. Cet épisode figure dans les annales indiennes comme le premier d'une pratique atroce qui perdure dans cet État de la plaine du Gange. Ces aveuglements à l'acide sont devenus le symbole d'une justice vengeresse et personnalisée, que certains citoyens se donnent le droit d'appliquer comme châtiment extrajudiciaire aux personnes «coupables» de transgresser l'ordre social.

La littérature, quant à elle, n'a pas attendu la vague d'études contemporaines pour se pencher sur la question des slums clearances et des urban poors, et faire écho aux développements sociopolitiques du pays. En 1980 déjà paraît en effet un des plus célèbres romans consacrés notamment à la thématique de la pauvreté urbaine, à savoir Basantī (traduction anglaise sous le même titre sortie en 2016) de l'auteur d'expression hindi Bhisham Sahni. Centré sur le personnage éponyme, une jeune fille d'immigrés indiens venus du Rajasthan s'établir dans un des slums de la capitale, le roman montre que contrairement aux promesses faites par Indira Gandhi et son fils à travers le slogan Garibi Hatao, il ne s'agissait pas tant d'éliminer la pauvreté que de déplacer, voire d'éradiquer, les pauvres (garib) eux-mêmes pour répondre à la dynamique d'embellissement de la ville.

Une perspective littéraire qui faisait écho au contre-discours ayant suivi l'état d'urgence dans les années 1977-1979, mais qui anticipait aussi l'émergence d'un courant historiographique majeur de la fin du $\mathrm{XX}^{\mathrm{e}}$ siècle, celui des Subaltern Studies, qui allait constituer une des composantes essentielles des études postcoloniales et dont le premier volume, dirigé par Ranajit Guha, parut en 1982. Dans ce courant de postmodernité naissante, une œuvre majeure était aussi sur le point de voir le jour en 1980: Les enfants de minuit (Midnight's Children) de Salman Rushdie. Ce roman, à sa parution en 1981, allait en effet changer à jamais le regard des Européens sur les littératures indiennes, tout en bouleversant à plus large échelle le monde de la fiction anglophone.

Enfin, l'année 1980 - à l'image de ce pays protéiforme - demande que l'on s'arrête aussi sur un événement qui sut raviver la fierté de toute une nation: la médaille d'or de hockey sur gazon aux Jeux olympiques de Moscou, une médaille enfin reconquise après vingt-six ans de disette, alors que l'équipe nationale avait dominé le hockey mondial de 1928 à 1964. Un événement qui passa sans nul doute complètement inaperçu en Suisse et en France, parfaitement dissimulé derrière un double écran: 
le rideau de fer séparant l'URSS de l'Europe occidentale et la fumée froide de la pipe que Jean-Paul Sartre venait de casser quelques mois auparavant.

Nicola Pozza

Section de langues et civilisations slaves et d'Asie du Sud, Faculté des lettres, Université de Lausanne

\section{BIBLIOGRAPHIE}

Chandra, Bipan, Mukherjee, Mridula, Mukherjee, Aditya, India After Independence: 1947-2000, Delhi, Penguin Books, 2000 (1999).

Jaffrelot, Christophe, Les nationalistes hindous. Idéologie, implantation et mobilisation des années 1920 aux années 1990, Paris, Presses de la Fondation nationale des sciences politiques, 1993.

Pouchepadass, Jacques, "Les Subaltern Studies ou la critique postcoloniale de la modernité», L'Homme, 156 (2000), p. 161-186.

Prakash, Gyan, Emergency Chronicles: Indira Gandhi and Democracy's Turning Point, Princeton/Oxford, Princeton University Press, 2019.

—, "Modi Reminds India of Indira Gandhi. Will He Share Her Electoral Fate?", The New York Times, 8 mai 2019, en ligne $<$ https://www.nytimes.com/2019/05/08/opinion/india-electionsmodi-gandhi.html>.

Puri, Balraj, "A Fuller View of the Emergency», Economic and Political Weekly, 28 (1995), p. 1736-1744.

SAHni, Bhisham, Basanti (1980), trad. anglaise du hindi par Shveta Sarda, Gurgaon, Penguin Books India, 2016. 
